\title{
TESTE DE ENVELHECIMENTO ACELERADO EM SEMENTES DE AVEIA PRETA ${ }^{1}$
}

\author{
SANDRA APARECIDA DE SOUZA², JOÃO NAKAGAWA², CARLA GOMES MACHADO²
}

\begin{abstract}
RESUMO - Objetivou-se com este trabalho, estudar o teste de envelhecimento acelerado tradicional (com água), em sementes de aveia preta com e sem tratamento fungicida, e o envelhecimento acelerado com solução saturada de cloreto de sódio $(\mathrm{NaCl})$, visando identificar o período de exposição e a temperatura para a classificação dos níveis de vigor de lotes dessas sementes. Foram utilizados cinco lotes de sementes, nos quais foram realizados testes para a caracterização da qualidade inicial de lotes (germinação, emergência de plântulas, condutividade elétrica, o comprimento de plântulas normais e massa de 1000 sementes), e estudado o envelhecimento acelerado tradicional (com água), com e sem tratamento fungicida, e o envelhecimento acelerado com solução saturada de sal $(\mathrm{NaCl})$ por períodos de $24,48,72,96$ e 120 horas de condicionamento às temperaturas de $40,43 \mathrm{e} 45^{\circ} \mathrm{C}$. O teste de envelhecimento acelerado é adequado para estimar o vigor de sementes de aveia preta pelo procedimento tradicional (com e sem tratamento fungicida) ou com solução saturada de sal, ambos a temperatura de $40^{\circ} \mathrm{C}$ por 24 horas.
\end{abstract}

Termos para indexação: vigor, qualidade fisiológica, Avena strigosa Schreb.

\section{ACCELERATED AGING TEST IN BLACK OAT SEEDS}

\begin{abstract}
The present work had as its objective to study the traditional method of accelerated aging (with water), in black oats seeds with and without fungicid treatment, and the accelerated aging with saturated solution of salt $(\mathrm{NaCl})$, by aiming to identify the exposition period and temperature that allow the classification of lots of black oats seeds in different vigour levels. The study was carried out by using five lots of black oats seeds. Tests were carried out to characterization of initial quality of the seed lots (tests of germination, seedlings emergency in the field, electrical conductivity, length of normal seedlings and mass of 1000 seeds) and the studies of accelerated aging consisted the traditional method (with water), with and without fungicid treatment, and accelerated aging with saturated solution of salt $(\mathrm{NaCl})$ for periods of 24, 48, 72, 96 and 120 hours, conditioning at temperatures of 40,43 and $45^{\circ} \mathrm{C}$. The studies concluded that the test of accelerated aging is adequated to evaluate the vigor of black oats seeds using the test of traditional accelerated aging (with and without treated seeds) or with saturated solution of salt, both at $40^{\circ} \mathrm{C}$ during 24 hours.
\end{abstract}

Index terms: vigor, physiological quality, Avena strigosa Schreb.

\footnotetext{
${ }^{1}$ Submetido em 21/08/2008. Aceito para publicação em 19/01/2009. Parte da Dissertação de Mestrado da primeira autora apresentada a FCA/UNESP, Botucatu - SP.

${ }^{2}$ Eng. Agr., doutorandas do Departamento de Produção Vegetal, FCA/ UNESP, souzasandra@fca.unesp.br, carlagm@fca.unesp.br
}

${ }^{3}$ Eng. Agr., Dr., Professor Titular Aposentado, Departamento de Produção Vegetal, FCA/UNESP, Rua José Barbosa de Barros, 1780, Caixa Postal 237, Fazenda Experimental Lageado, CEP 18610-307, Botucatu, SP. secdamv@fca.unesp.br 


\section{INTRODUÇÃO}

O uso de sementes de alta qualidade é de grande importância na implantação e no estabelecimento da lavoura no campo. $\mathrm{O}$ vigor das sementes pode afetar não só $\mathrm{o}$ estabelecimento, mas também influenciar o crescimento, o desenvolvimento e a produtividade das plantas.

A aveia preta (Avena strigosa Schreb.) é uma gramínea adaptada tanto a região temperada quanto subtropical e se tem destacado nos cultivos de inverno em razão de ser produtora de massa; possuir abundante massa radicular, melhorando as condições físicas e biológicas do solo além de controlar doenças e invasoras. É também, recomendada em rotação de culturas pela decomposição mais lenta que leguminosas empregadas como adubo verde (Derpsch \& Calegari, 1992).

Os testes empregados para a determinação da qualidade fisiológica das sementes são os de germinação e vigor, dentre estes se destaca o teste de envelhecimento acelerado, que foi desenvolvido para avaliar o vigor de sementes, tentando estimar o potencial de armazenamento das sementes principalmente em relação à umidade e temperaturas elevadas. Baseia-se no princípio de que se aumentar a temperatura e a umidade elevam-se a taxa de deterioração das sementes, sendo a deterioração variável de acordo com o seu vigor inicial (Marcos Filho et al., 1987).

Por apresentar resultados confiáveis em curto período de tempo, o teste de envelhecimento acelerado tem sido adotado para a determinação de vigor de diversas espécies (McDonald, 1995), sendo considerado pela International Seed Testing Association - ISTA suficientemente padronizado para avaliar o vigor de sementes de soja e sugerido para ser aplicado em sementes de milho (Hampton \& Tekrony, 1995).

Vários fatores podem afetar o comportamento das sementes durante o teste de envelhecimento acelerado, indicando valores diferentes em relação ao vigor, tais como: temperatura, período de exposição das sementes, grau de umidade inicial das sementes, abertura da câmara durante o teste, tratamento fungicida, tamanho da amostra e genótipo (Marcos Filho, 1999).

No teste de envelhecimento acelerado tradicional (com água), as diferenças na absorção de água pelas sementes, expostas à atmosfera com alta umidade relativa podem originar variações acentuadas no grau de umidade das sementes (Torres, 2002). Além disso, as elevadas condições de temperatura e umidade relativa do ar durante o teste propiciam a deterioração das sementes, provocando o aparecimento de plântulas anormais ou de sementes mortas (McDonald et al., 1993). Marcos Filho (1994) relatou ainda que estas condições podem inibir a manifestação de alguns microrganismos; assim, os dados obtidos no teste de envelhecimento podem ser superiores aos observados no teste de germinação. McDonald et al. (1993), entretanto, observaram efeito positivo do tratamento fungicida em sementes de soja infestadas com Aspergillus glaucus e Aspergillus niger, elevando a germinação destas sementes após o envelhecimento acelerado.

Neste sentido, o teste de envelhecimento acelerado com solução saturada de sal vem sendo utilizado como alternativa por possibilitar a obtenção de valores de umidade relativa em níveis menores do que os observados no envelhecimento acelerado tradicional (com água), impedindo o crescimento de microrganismos e minimizando os efeitos de patógenos associados às sementes (Jianhua \& McDonald, 1996). Resultados eficientes do teste de envelhecimento acelerado com soluções saturadas de sal têm sido observados em vários trabalhos de pesquisa (Rodo et al., 2000; Panobianco \& Marcos Filho, 2001; Torres, 2002); no entanto, as temperaturas e períodos de exposição variam de acordo com a espécie em estudo, de 38 a $45^{\circ} \mathrm{C}$ e 24 a 120 horas.

Dentre os testes utilizados para avaliar o vigor das sementes, o teste de envelhecimento acelerado tem apresentado boas correlações com a emergência de plântulas em campo para sementes de diversas espécies (Panobianco \& Marcos Filho, 2001; Torres, 2002; Dias et al., 2003). Segundo Borsato et al. (2000), em estudos realizados com lotes de aveia branca, a percentagem de emergência de plântulas foi maior do que a germinação observada no teste de envelhecimento acelerado, quando submetidas aos períodos de exposição de $48,60,72$ e 84 horas a $42^{\circ} \mathrm{C}$, sendo o período de 48 horas o que mais se aproximou dos dados obtidos na emergência.

O teste de envelhecimento acelerado tradicional tem sido realizado em sementes de aveia preta a $42^{\circ} \mathrm{C}$ por 48 horas (Nakagawa et al., 1994; Nakagawa et al., 1995; Paterniani et al., 1995), porém sem respaldo em pesquisa específica para a espécie. Garcia \& Menezes (1999), estudando a metodologia do teste, testaram uma única temperatura $\left(41^{\circ} \mathrm{C}\right)$ e verificaram que 24 horas foi o melhor período de condicionamento. Neste sentido, a metodologia do teste de envelhecimento acelerado precisa ser aprimorada para avaliação do vigor das sementes dessa espécie.

Objetivou-se com o presente trabalho estudar a metodologia do teste de envelhecimento acelerado tradicional (com e sem tratamento fungicida) e com solução saturada de cloreto de sódio para a classificação de níveis de vigor em lotes de sementes de aveia preta. 


\section{MATERIAL E MÉTODOS}

O trabalho foi desenvolvido no Laboratório de Análise de Sementes do Departamento de Produção Vegetal da Faculdade de Ciências Agronômicas, Campus de Botucatu - UNESP, utilizando-se cinco lotes de sementes de aveia preta, de procedências comerciais ou produzidas na Fazenda Experimental Lageado do Campus de Botucatu.

Foram realizados testes para a caracterização da qualidade inicial dos lotes e estudados metodologias do teste de envelhecimento acelerado com cinco períodos de condicionamento $(24,48,72,96$ e 120 horas) e três temperaturas $\left(40,43\right.$ e $\left.45^{\circ} \mathrm{C}\right)$ nos procedimentos tradicional com água, com e sem tratamento fungicida das sementes, e com solução saturada de sal $(\mathrm{NaCl})$.

Caracterização da qualidade inicial dos lotes: Determinação do teor de água - $\mathrm{O}$ teor de água das sementes foi determinado pelo método da estufa, a $105 \pm$ $3^{\circ} \mathrm{C}$ durante 24 horas (Brasil, 1992), com a utilização de quatro subamostras. Massa de 1000 sementes - Foi realizado utilizando-se oito subamostras de 100 sementes (Brasil, 1992). Teste de germinação - Realizado com quatro subamostras de 50 sementes em temperatura de $20^{\circ} \mathrm{C}$, utilizando-se papel toalha (EP) umedecido com água na proporção de duas vezes a massa do papel. As contagens foram realizadas aos cinco e 10 dias (Brasil, 1992). Emergência de plântulas Realizado no campo com quatro repetições de 100 sementes, distribuídas em sulcos de quatro metros de comprimento, com três centímetros de profundidade e distância entre sulcos de $20 \mathrm{~cm}$; 21 dias após a semeadura foi feita a contagem das plântulas emergidas. Condutividade elétrica - Foi conduzido por meio do sistema de massa, com quatro repetições de 50 sementes. Foram determinadas as massas das sementes e, em seguida, estas foram colocadas em copos plásticos com $75 \mathrm{~mL}$ de água destilada e mantidas a $25^{\circ} \mathrm{C}$. Após 24 horas de embebição foi determinada a condutividade elétrica da solução (Vieira \& Krzyzanowski, 1999). Comprimento das plântulas - Foi realizado em rolo de papel toalha (EP), com quatro repetições a $20^{\circ} \mathrm{C}$. O papel foi umedecido com duas vezes a massa do papel, onde foram colocadas 15 sementes. Após o período de cinco dias no germinador, foi realizada a medição da parte aérea e da raiz principal das plântulas normais. O comprimento médio de cada parte foi obtido somando-se as medidas de cada plântula em cada repetição e dividindo-se, a seguir, pelo número de plântulas normais obtidas no teste (Nakagawa, 1994).

Experimentos: Envelhecimento acelerado tradicional (com água) sem tratamento fungicida - Foi desenvolvido utilizando-se 250 sementes para cada lote e condição estudada; as sementes foram colocadas em caixa de plástico $(11,0 \times 11,0 \times 3,5 \mathrm{~cm})$, com a utilização de uma caixa para cada lote avaliado. As sementes foram distribuídas sobre uma tela de alumínio fixada na caixa (McDonald Jr \& Phaneendranath, 1978); no interior da caixa foram adicionados $40 \mathrm{~mL}$ de água e, em seguida, os recipientes foram levados a incubadoras reguladas a temperaturas de 40,43 ou $45^{\circ} \mathrm{C}$ e os tempos de permanência das sementes nas condições descritas foram 24, 48, 72, 96 ou 120 horas. Decorridos esses períodos, 200 sementes foram divididas em quatro subamostras de 50 sementes e foi instalado o teste de germinação. A contagem do número de plântulas normais foi realizada após cinco dias de permanência das sementes no germinador, mantido a $20^{\circ} \mathrm{C}$. Após o envelhecimento das sementes foi determinado o teor de água utilizando-se 50 sementes, subdivididas em quatro subamostras, pelo método da estufa a $105 \pm 3{ }^{\circ} \mathrm{C}$ por 24h (Brasil, 1992). Envelhecimento acelerado com solução saturada de sal (NaCl) - Foi realizado da mesma maneira descrita para o estudo do teste tradicional com água, com exceção de terem sido adicionados ao fundo de cada caixa plástica (compartimento individual), $40 \mathrm{~mL}$ de solução saturada de $\mathrm{NaCl}$, em substituição à água. Essa solução foi obtida por meio da proporção $40 \mathrm{~g}$ de $\mathrm{NaCl} 100 \mathrm{~mL}^{-1} \mathrm{de}$ água (solução saturada), estabelecendo, com isso, ambiente com $76 \%$ de umidade relativa do ar (Jianhua \& McDonald, 1996). Envelhecimento acelerado tradicional (com água) com tratamento fungicida - Foi realizado com a mesma metodologia descrita para o estudo do teste tradicional com a diferença de que as sementes foram tratadas com o produto Vitavax-Thiram $200 \mathrm{SC}\left(250 \mathrm{~mL} 100 \mathrm{~kg}^{-1}\right.$ de sementes $)$ antes da realização do teste de envelhecimento.

O delineamento experimental utilizado foi o inteiramente casualizado e as médias, exceto o teor de água, foram comparadas pelo teste de Tukey, a 5\% de probabilidade.

\section{RESULTADOS E DISCUSSÃO}

O teor de água inicial das sementes (Tabela 1) foi semelhante entre os lotes de aveia preta. Segundo Marcos Filho (1999) é conveniente a comparação de amostras que apresentam o mesmo grau de umidade antes do envelhecimento; no entanto, diferenças de 1 a $2 \%$ entre as amostras não comprometem os resultados do teste.

Os dados referentes ao teste de germinação indicaram a maior porcentagem de germinação para o lote 4, 
porém todos os demais lotes $(1,2,3$ e 5$)$ estavam dentro do padrão para comercialização de sementes de aveia preta no estado de São Paulo, ou seja, 75\% (CESM/SP, 2001) É importante que as amostras avaliadas tenham germinação semelhante ou compatível com os padrões estabelecidos para a comercialização, pois um dos objetivos do teste de envelhecimento acelerado é identificar diferenças significativas na qualidade fisiológica de lotes comercializáveis, principalmente entre os que possuem poder germinativo semelhante (Marcos Filho, 1999).

TABELA 1. Dados médios do teor de água inicial das sementes (TA) germinação (G), emergência de plântulas (EP), comprimento de parte das plântulas $(\mathrm{RN}$ = raiz de normal, $\mathrm{PAN}$ = parte aérea de normal), condutividade elétrica (CE) e massa de 1000 sementes (M 1000) de cinco lotes de sementes de aveia preta.

\begin{tabular}{|c|c|c|c|c|c|c|c|}
\hline \multirow{2}{*}{ Lotes } & \multirow{2}{*}{$\begin{array}{l}\text { TA } \\
(\%)\end{array}$} & \multirow{2}{*}{$\begin{array}{c}\mathrm{G} \\
(\%)\end{array}$} & \multirow{2}{*}{$\begin{array}{l}\mathrm{EP} \\
(\%)\end{array}$} & \multicolumn{2}{|c|}{$\begin{array}{c}\text { Comprimento de partes das } \\
\text { plântulas }(\mathrm{cm})\end{array}$} & \multirow{2}{*}{$\begin{array}{c}\mathrm{CE} \\
\mu \mathrm{S} \cdot \mathrm{g}^{-1} \cdot \mathrm{cm}^{-1}\end{array}$} & \multirow{2}{*}{ M $1000(\mathrm{~g})$} \\
\hline & & & & $\mathrm{RN}$ & PAN & & \\
\hline 1 & 12 & $84 \mathrm{~b}$ & $68 b c$ & $8,3 \mathrm{ab}$ & $5,0 \mathrm{a}$ & $81,5 \mathrm{~b}$ & $20,8 \mathrm{a}$ \\
\hline 2 & 11 & $86 \mathrm{~b}$ & $75 \mathrm{ab}$ & $8,5 \mathrm{a}$ & $5,0 \mathrm{a}$ & 56,8 a & $18,0 \mathrm{c}$ \\
\hline 3 & 12 & $83 \mathrm{~b}$ & $64 \mathrm{c}$ & $6,0 \mathrm{c}$ & $5,0 \mathrm{a}$ & $115,5 \mathrm{c}$ & $16,0 \mathrm{~d}$ \\
\hline 4 & 12 & $94 \mathrm{a}$ & $83 \mathrm{a}$ & $9,0 \mathrm{a}$ & $6,0 \mathrm{a}$ & $45,0 \mathrm{a}$ & $19,9 \mathrm{~b}$ \\
\hline 5 & 12 & $84 \mathrm{~b}$ & $66 \mathrm{bc}$ & $6,5 \mathrm{bc}$ & $5,0 \mathrm{a}$ & $114,0 \mathrm{c}$ & $16,1 \mathrm{~d}$ \\
\hline $\mathrm{CV}(\%)$ & - & 1,8 & 6,2 & 11,1 & 9,9 & 8,1 & 3,1 \\
\hline DMS (\%) & - & 3,3 & 9,7 & 1,8 & 1,1 & 14,6 & 0,8 \\
\hline
\end{tabular}

* Médias seguidas de letras distintas na coluna diferem entre si pelo teste de Tukey a $5 \%$ de probabilidade.

Pelos resultados do teste de emergência de plântula observam-se diferenças significativas entre os lotes avaliados, apontando o lote 4 como o de melhor qualidade fisiológica e o lote 3 como o de pior qualidade. Em todos os lotes avaliados foram verificadas reduções na porcentagem média de plântulas normais emergidas por ocasião da avaliação 21 dias após a semeadura. Este fato deve-se às condições do ambiente que, por não serem as mais adequadas para a germinação, propiciaram redução na germinação das sementes.

No teste de comprimento de plântulas (Tabela 1) foram medidas a raiz primária e a parte aérea das plântulas normais e anormais aos cinco dias da germinação. O comprimento médio da raiz primária das plântulas normais classificou os lotes 4 e 3 , respectivamente, como os extremos de valor superior e inferior. Já para os dados médios de parte aérea das plântulas normais e anormais e raiz primária de plântulas anormais não foram verificadas diferenças significativas entre os lotes.

Com o teste de condutividade elétrica (Tabela 1) foi possível os lotes em três níveis de vigor, identificando os lotes 4 e 2 como os de melhor qualidade, o 1 como o de qualidade intermediária e 3 e 5 como os de pior qualidade. As avaliações do comprimento da raiz primária normal e da emergência de plântulas indicaram essa mesma ordenação dos lotes de sementes.

Para os resultados de massa de 1000 sementes (Tabela 1) verificou-se que as sementes do lote 1 foram as que apresentaram maior massa, seguido dos lotes 4, 2, 5 e 3 . As sementes maiores e as de maior densidade são as que possuem, normalmente, embriões bem formados e com maiores quantidades de reservas, potencialmente, as mais vigorosas (Carvalho e Nakagawa, 2000). Os resultados de massa de 1000 sementes assemelham-se aos dos testes de emergência de plântulas, comprimento de raiz primária de plântulas normais e condutividade elétrica, nos quais as sementes com maiores massas foram, de maneira geral, mais vigorosas, com exceção do lote 1 , que foi classificado como o de vigor intermediário.O teste de envelhecimento acelerado tradicional com água (Tabela 2) possibilitou as separações dos lotes em três níveis de vigor nos períodos de 24 e 48 horas, à temperatura de $40^{\circ} \mathrm{C}$ e de 48 horas a $43^{\circ} \mathrm{C}$ e $45^{\circ} \mathrm{C}$. Os períodos de 96 e 120 horas de condicionamento a $45^{\circ} \mathrm{C}$ provocaram a ausência de plântulas normais em praticamente todos os lotes. Esses resultados assemelhamse aos observados por Wetzel (1972), que constatou ser o período de 48 horas de envelhecimento menos severo e mais efetivo para avaliar o vigor de sementes de trigo. A redução 
observada na germinação pode ter sido causada tanto pelo alto teor de água atingido pelas sementes e a temperatura elevada $\left(45^{\circ} \mathrm{C}\right)$ como, também, pela presença de microrganismos associados às sementes.

TABELA 2. Germinação de sementes de cinco lotes de aveia preta, após cinco períodos de condicionamento $(24,48$, $72,96,120$ horas) à temperatura de 40,43 e $45^{\circ} \mathrm{C}$ para o teste de envelhecimento acelerado tradicional com água.

\begin{tabular}{|c|c|c|c|c|c|c|c|c|c|c|c|c|c|c|c|}
\hline \multicolumn{16}{|c|}{ Germinação após envelhecimento acelerado(\%) } \\
\hline \multirow{2}{*}{ Lotes } & \multicolumn{5}{|c|}{$40^{\circ} \mathrm{C}$} & \multicolumn{5}{|c|}{$43^{\circ} \mathrm{C}$} & \multicolumn{5}{|c|}{$45^{\circ} \mathrm{C}$} \\
\hline & $24 \mathrm{~h}$ & $48 \mathrm{~h}$ & $72 \mathrm{~h}$ & $96 \mathrm{~h}$ & $120 \mathrm{~h}$ & $24 \mathrm{~h}$ & $48 \mathrm{~h}$ & $72 \mathrm{~h}$ & $96 \mathrm{~h}$ & $120 \mathrm{~h}$ & $24 \mathrm{~h}$ & $48 \mathrm{~h}$ & $72 \mathrm{~h}$ & $96 \mathrm{~h}$ & $120 \mathrm{~h}$ \\
\hline 1 & $78 \mathrm{c}$ & $75 c$ & $72 b$ & $53 b$ & $28 b$ & $77 b$ & $71 \mathrm{c}$ & $63 b$ & $43 b$ & $34 b$ & $67 \mathrm{bc}$ & $33 \mathrm{c}$ & $10 \mathrm{~b}$ & $0 \mathrm{~b}$ & 0a \\
\hline 2 & $85 b$ & $87 \mathrm{~b}$ & $83 \mathrm{a}$ & $74 \mathrm{a}$ & $48 \mathrm{a}$ & $81 b$ & $80 \mathrm{~b}$ & $80 a$ & $71 \mathrm{a}$ & $47 a$ & $76 b$ & $73 b$ & $38^{\mathrm{a}}$ & $2 \mathrm{a}$ & $1 \mathrm{a}$ \\
\hline 3 & $76 c$ & $74 c$ & $66 b$ & $45 c$ & $28 b$ & $75 b$ & $72 \mathrm{c}$ & $62 b$ & $41 b$ & $27 b c$ & $61 \mathrm{c}$ & $32 \mathrm{c}$ & $12 b$ & $0 \mathrm{~b}$ & $0 \mathrm{a}$ \\
\hline 4 & $93 a$ & $95 a$ & $84 a$ & $80 a$ & $48 \mathrm{a}$ & $90 \mathrm{a}$ & $90 \mathrm{a}$ & $84 a$ & $75 a$ & $49 a$ & $89 a$ & $85 a$ & $33^{\mathrm{a}}$ & $3 a$ & $0 \mathrm{a}$ \\
\hline 5 & $79 c$ & $72 c$ & $70 \mathrm{~b}$ & $50 \mathrm{bc}$ & $24 b$ & $76 b$ & $73 c$ & $60 \mathrm{~b}$ & $43 b$ & $23 c$ & $67 \mathrm{bc}$ & $32 c$ & $12 b$ & $0 \mathrm{~b}$ & $0 \mathrm{a}$ \\
\hline C.V.(\%) & 3,2 & 2,7 & 4,6 & 4,8 & 12,9 & 3,4 & 3,3 & 3,2 & 6,3 & 13,0 & 6,4 & 5,4 & 17,1 & 95,2 & 447,2 \\
\hline DMS (\%) & 5,8 & 4,7 & 7,4 & 6,3 & 9,8 & 5,9 & 5,6 & 4,9 & 7,5 & 10,1 & 10,1 & 5,5 & 7,8 & 1,9 & 1,0 \\
\hline
\end{tabular}

*Médias seguidas de letras distintas na coluna diferem entre si pelo teste de Tukey a 5\% de probabilidade

O teor de água das sementes após o envelhecimento acelerado tradicional (Tabela 3) à temperatura de $40^{\circ} \mathrm{C}$ foi semelhante entre os cinco lotes avaliados no período de 24 e 120 horas, enquanto que para os períodos de 48, 72 e $96 \mathrm{~h}$ de condicionamento verificou-se menor teor de água para o lote 4 . Na temperatura de $43^{\circ} \mathrm{C}$ (Tabela 3), foram observadas diferenças entre os lotes em todos os períodos de condicionamento. A temperatura de $45^{\circ} \mathrm{C}$ mostrou que somente o período de 96 horas foi semelhante entre os cinco lotes avaliados. Os demais períodos, apesar de haver diferença entre os lotes, a variação ficou entre 1,0 e 2,8\% de água.

TABELA 3. Grau de umidade de sementes de cinco lotes de aveia preta, após cinco períodos de condicionamento (24, $48,72,96,120$ horas) à temperatura de 40,43 e $45^{\circ} \mathrm{C}$ para o teste de envelhecimento acelerado tradicional com água.

\begin{tabular}{|c|c|c|c|c|c|c|c|c|c|c|c|c|c|c|c|}
\hline \multicolumn{16}{|c|}{ Teor de água (\%) } \\
\hline \multirow{2}{*}{ Lotes } & \multicolumn{5}{|c|}{$40^{\circ} \mathrm{C}$} & \multicolumn{5}{|c|}{$43^{\circ} \mathrm{C}$} & \multicolumn{5}{|c|}{$45^{\circ} \mathrm{C}$} \\
\hline & $24 \mathrm{~h}$ & $48 \mathrm{~h}$ & $72 \mathrm{~h}$ & $96 \mathrm{~h}$ & $120 \mathrm{~h}$ & $24 \mathrm{~h}$ & $48 \mathrm{~h}$ & $72 \mathrm{~h}$ & $96 \mathrm{~h}$ & $120 \mathrm{~h}$ & $24 \mathrm{~h}$ & $48 \mathrm{~h}$ & $72 \mathrm{~h}$ & $96 h$ & $120 \mathrm{~h}$ \\
\hline 1 & 27,8 & 32,8 & 33,0 & 33,0 & 33,5 & 25,0 & 30,0 & 31,0 & 31,0 & 31,0 & 27,5 & 29,0 & 32,5 & 33,0 & 31,0 \\
\hline 2 & 26,5 & 32,5 & 33,8 & 33,0 & 31,3 & 25,8 & 27,3 & 29,0 & 30,8 & 29,3 & 26,5 & 30,0 & 31,5 & 32,0 & 31,3 \\
\hline 3 & 28,5 & 33,0 & 33,3 & 33,8 & 33,3 & 26,5 & 28,5 & 32,5 & 32,3 & 33,3 & 27,0 & 29,3 & 30,5 & 32,3 & 33,5 \\
\hline 4 & 28,3 & 29,5 & 31,0 & 31,0 & 31,8 & 24,0 & 28,0 & 29,0 & 30,5 & 30,5 & 25,3 & 28,0 & 31,5 & 32,3 & 31,3 \\
\hline 5 & 27,3 & 33,5 & 33,5 & 33,8 & 32,5 & 27,8 & 30,3 & 31,8 & 33,0 & 33,5 & 28,0 & 29,0 & 33,0 & 32,8 & 33,5 \\
\hline
\end{tabular}

Segundo Marcos Filho (1999), o grau de umidade das sementes após o envelhecimento é um dos principais indicadores da uniformidade das condições do teste, as variações de 3 a $4 \%$ entre as amostras são consideradas toleráveis; portanto, os resultados obtidos do teor de água a 40,43 e $45^{\circ} \mathrm{C}$ após o envelhecimento foram considerados toleráveis, pois as diferenças ocorridas foram inferiores a $4 \%$ entre os lotes. 
Para o teste de envelhecimento acelerado com solução saturada de sal $(\mathrm{NaCl})$ (Tabela 4), observou-se que, de um modo geral, o período de 24 horas de condicionamento foi o que melhor classificou os lotes em três níveis de vigor nas três temperaturas utilizadas. A porcentagem de germinação com este procedimento manteve-se elevada mesmo em condições de longos períodos de condicionamento, principalmente nos lotes classificados como os mais vigorosos (lotes 4 e 2). Isto se deve ao menor teor de água das sementes e a ausência do desenvolvimento aparente de microrganismos. O teste de envelhecimento acelerado com solução saturada de sal foi o que promoveu efeitos menos drásticos sobre a germinação das sementes, mesmo assim, foi eficiente na separação dos lotes.

TABELA 4. Germinação de sementes de cinco lotes de aveia preta, após cinco períodos de condicionamento (24, 48, 72, 96, 120 horas) à temperatura de 40,43 e $45^{\circ} \mathrm{C}$ para o teste de envelhecimento acelerado com solução saturada de sal ( $\mathrm{NaCl})$.

\begin{tabular}{|c|c|c|c|c|c|c|c|c|c|c|c|c|c|c|c|}
\hline \multicolumn{16}{|c|}{ Germinação após envelhecimento acelerado (\%) } \\
\hline & \multicolumn{5}{|c|}{$40^{\circ} \mathrm{C}$} & \multicolumn{5}{|c|}{$43^{\circ} \mathrm{C}$} & \multicolumn{5}{|c|}{$45^{\circ} \mathrm{C}$} \\
\hline Lotes & $24 \mathrm{~h}$ & $48 \mathrm{~h}$ & $72 \mathrm{~h}$ & $96 \mathrm{~h}$ & $120 \mathrm{~h}$ & $24 \mathrm{~h}$ & $48 \mathrm{~h}$ & $72 \mathrm{~h}$ & $96 \mathrm{~h}$ & $120 \mathrm{~h}$ & $24 \mathrm{~h}$ & $48 \mathrm{~h}$ & $72 \mathrm{~h}$ & $96 \mathrm{~h}$ & $120 \mathrm{~h}$ \\
\hline 1 & $78 \mathrm{c}$ & $76 \mathrm{c}$ & $73 \mathrm{bc}$ & $71 \mathrm{c}$ & $71 \mathrm{c}$ & $74 \mathrm{c}$ & $72 \mathrm{bc}$ & $70 \mathrm{c}$ & $68 \mathrm{bc}$ & $70 \mathrm{c}$ & $77 \mathrm{c}$ & $73 c$ & $72 \mathrm{c}$ & $62 c$ & $46 \mathrm{c}$ \\
\hline 2 & $86 b$ & $83 b$ & $80 \mathrm{ab}$ & $79 b$ & $78 b$ & $83 b$ & $78 b$ & $80 \mathrm{~b}$ & $77 \mathrm{ab}$ & $78 b$ & $85 b$ & $81 b$ & $81 b$ & $73 b$ & $74 b$ \\
\hline 3 & $76 \mathrm{c}$ & $76 c$ & $72 b c$ & $56 \mathrm{~d}$ & $48 \mathrm{~d}$ & $72 \mathrm{c}$ & $70 \mathrm{c}$ & $67 c$ & $63 c$ & $53 \mathrm{~d}$ & $72 c$ & $70 \mathrm{~cd}$ & $72 c$ & $47 d$ & $43 c$ \\
\hline 4 & $98 \mathrm{a}$ & $97 \mathrm{a}$ & $85 a$ & $85 a$ & $89 a$ & $95 a$ & $94 a$ & $93 a$ & $84 a$ & $88 \mathrm{a}$ & $93 a$ & $91 \mathrm{a}$ & $93 a$ & $83 a$ & $82 \mathrm{a}$ \\
\hline 5 & $77 \mathrm{c}$ & $72 c$ & $66 c$ & $68 \mathrm{c}$ & $70 c$ & $72 c$ & $68 \mathrm{c}$ & $65 c$ & $50 \mathrm{~d}$ & $50 \mathrm{~d}$ & $74 \mathrm{c}$ & $68 \mathrm{~d}$ & $57 d$ & $50 \mathrm{~d}$ & $48 \mathrm{c}$ \\
\hline C.V.(\%) & 2,7 & 3,4 & 5 & 3,7 & 3,5 & 3,5 & 5 & 5,6 & 6,1 & 4,6 & 4,2 & 2,6 & 5,1 & 4,2 & 6,6 \\
\hline DMS (\%) & 4,9 & 5,9 & 8,2 & 5,8 & 5,4 & 6,1 & 8,2 & 9,1 & 9,1 & 6,8 & 7,3 & 4,4 & 8,2 & 5,7 & 8,4 \\
\hline
\end{tabular}

*Médias seguidas de letras distintas na coluna diferem entre si pelo teste de Tukey a $5 \%$ de probabilidade

Os dados referentes ao teor de água das sementes após o envelhecimento com solução salina a temperatura de $40^{\circ} \mathrm{C}$ (Tabela 5) não apresentaram variação entre os lotes para todos os períodos. À temperatura de $43^{\circ} \mathrm{C}$, os teores de água variaram de 11,8 a $14,0 \%$. Já na temperatura de $45^{\circ} \mathrm{C}$ foram observadas diferenças entre os lotes, porém inferiores a $3 \%$.

TABELA 5. Teor de água de sementes de cinco lotes de aveia preta, após cinco períodos de condicionamento (24, 48, $72,96,120$ horas) à temperatura de 40,43 e $45^{\circ} \mathrm{C}$ para o teste de envelhecimento acelerado com solução saturada de sal $(\mathrm{NaCl})$.

\begin{tabular}{|c|c|c|c|c|c|c|c|c|c|c|c|c|c|c|c|}
\hline \multicolumn{16}{|c|}{ Teor de água (\%) } \\
\hline \multirow{2}{*}{ Lotes } & \multicolumn{5}{|c|}{$40^{\circ} \mathrm{C}$} & \multicolumn{5}{|c|}{$43^{\circ} \mathrm{C}$} & \multicolumn{5}{|c|}{$45^{\circ} \mathrm{C}$} \\
\hline & $24 \mathrm{~h}$ & $48 \mathrm{~h}$ & $72 \mathrm{~h}$ & $96 \mathrm{~h}$ & $120 \mathrm{~h}$ & $24 \mathrm{~h}$ & $48 \mathrm{~h}$ & $72 \mathrm{~h}$ & $96 \mathrm{~h}$ & $120 \mathrm{~h}$ & $24 \mathrm{~h}$ & $48 \mathrm{~h}$ & $72 \mathrm{~h}$ & $96 h$ & $120 \mathrm{~h}$ \\
\hline 1 & 12,8 & 13,0 & 13,3 & 12,5 & 13,0 & 11,8 & 12,8 & 13,3 & 14,0 & 13,0 & 13,0 & 12,5 & 12,0 & 12,3 & 11,5 \\
\hline 2 & 13,0 & 12,5 & 12,8 & 12,5 & 12,5 & 13,0 & 13,0 & 13,0 & 13,0 & 13,0 & 12,8 & 12,5 & 11,8 & 12,0 & 12,0 \\
\hline 3 & 12,3 & 13,0 & 13,5 & 12,0 & 13,0 & 12,5 & 12,5 & 13,0 & 13,0 & 12,8 & 12,0 & 12,8 & 11,8 & 11,8 & 12,0 \\
\hline 4 & 13,0 & 12,8 & 12,5 & 12,8 & 13,0 & 13,5 & 13,0 & 13,0 & 13,3 & 13,0 & 12,5 & 12,3 & 12,0 & 12,0 & 12,3 \\
\hline 5 & 12,8 & 13,0 & 13,3 & 12,0 & 13,5 & 13,3 & 12,8 & 12,8 & 13,3 & 12,0 & 12,3 & 12,5 & 12,0 & 12,0 & 13,0 \\
\hline
\end{tabular}


Pelos resultados obtidos observou-se que mesmo com teor de água inferior em relação ao teste de envelhecimento tradicional, houve redução na porcentagem de germinação a progressivamente conforme o aumento da temperatura (Tabela 4), evidenciando o efeito da temperatura sobre a redução na porcentagem de germinação. No entanto, os resultados são menos drásticos que os observados para o envelhecimento acelerado tradicional (Tabela 2). Segundo Jianhua \& McDonald (1996), no teste de envelhecimento acelerado com solução saturada de sal, mesmo com teor de água inferior, ocorre estresse suficiente para reduzir a germinação.

Com o uso da solução saturada de sal, houve redução dos valores do teor de água das sementes após o envelhecimento e os resultados foram mais uniformes. Estes resultados se assemelham com os verificados por Panobianco \& Marcos Filho (2001) em estudos realizados com sementes de tomate.

O teste de envelhecimento acelerado tradicional com o tratamento fungicida das sementes (Tabela 6) mostrouse menos drástico que o teste de envelhecimento acelerado tradicional sem o tratamento fungicida (Tabela 2). Neste teste, os períodos que mais evidenciaram as diferenças entre os lotes foram os de 24 e 48 horas à temperatura de $40^{\circ} \mathrm{C}, 48$ e 72 horas à temperatura de $43^{\circ} \mathrm{C}$ e 24 e 120 horas a $45^{\circ} \mathrm{C}$.

TABELA 6. Germinação de sementes de cinco lotes de aveia preta, tratadas com fungicida, após cinco períodos de condicionamento $(24,48,72,96,120$ horas $)$ à temperatura de 40,43 e $45^{\circ} \mathrm{C}$ para o teste de envelhecimento acelerado tradicional.

\begin{tabular}{|c|c|c|c|c|c|c|c|c|c|c|c|c|c|c|c|}
\hline \multicolumn{16}{|c|}{ Germinação após envelhecimento acelerado (\%) } \\
\hline \multirow{2}{*}{ Lotes } & \multicolumn{5}{|c|}{$40^{\circ} \mathrm{C}$} & \multicolumn{5}{|c|}{$43^{\circ} \mathrm{C}$} & \multicolumn{5}{|c|}{$45^{\circ} \mathrm{C}$} \\
\hline & $24 \mathrm{~h}$ & $48 \mathrm{~h}$ & $72 \mathrm{~h}$ & $96 \mathrm{~h}$ & $120 \mathrm{~h}$ & $24 \mathrm{~h}$ & $48 \mathrm{~h}$ & $72 \mathrm{~h}$ & $96 \mathrm{~h}$ & $120 \mathrm{~h}$ & $24 \mathrm{~h}$ & $48 \mathrm{~h}$ & $72 \mathrm{~h}$ & $96 \mathrm{~h}$ & $120 \mathrm{~h}$ \\
\hline 1 & $77 \mathrm{c}$ & $75 \mathrm{c}$ & $69 \mathrm{bc}$ & $62 b$ & $40 \mathrm{c}$ & $75 \mathrm{bc}$ & $73 c$ & $68 \mathrm{c}$ & $48 \mathrm{bc}$ & $39 b$ & $73 \mathrm{c}$ & $70 \mathrm{bc}$ & $69 \mathrm{bc}$ & $36 b$ & $22 c$ \\
\hline 2 & $85 b$ & $83 b$ & $80 \mathrm{ab}$ & $66 \mathrm{ab}$ & $58 \mathrm{ab}$ & $82 b$ & $79 b$ & $80 \mathrm{~b}$ & $59 \mathrm{ab}$ & $63 a$ & $84 b$ & $76 b$ & $81 \mathrm{ab}$ & $54 a$ & $34 b$ \\
\hline 3 & $75 c$ & $73 c$ & $70 \mathrm{bc}$ & $50 \mathrm{c}$ & $33 c$ & $74 c$ & $69 c$ & $66 c$ & $48 b c$ & $39 b$ & $73 c$ & $61 \mathrm{c}$ & $66 c$ & $29 b$ & $19 \mathrm{c}$ \\
\hline 4 & $96 a$ & $94 a$ & $87 a$ & $72 \mathrm{a}$ & $70 \mathrm{a}$ & $96 a$ & $95 a$ & $94 a$ & $74 a$ & $65 a$ & $93 a$ & $90 \mathrm{a}$ & $88 \mathrm{a}$ & $59 a$ & $46 a$ \\
\hline 5 & $75 c$ & $71 \mathrm{c}$ & $66 c$ & $45 c$ & $44 \mathrm{bc}$ & $73 c$ & $71 \mathrm{c}$ & $64 c$ & $41 c$ & $32 b$ & $71 \mathrm{c}$ & $66 \mathrm{bc}$ & $56 c$ & $31 b$ & $19 \mathrm{c}$ \\
\hline C.V.(\%) & 2,6 & 2,7 & 7,1 & 7,3 & 14,5 & 4,2 & 3 & 5,2 & 13,5 & 18,3 & 4,2 & 7,1 & 8,5 & 16 & 13,0 \\
\hline DMS (\%) & 4,5 & 4,7 & 11,4 & 9,3 & 15,4 & 7,2 & 5,1 & 8,5 & 15,8 & 18,9 & 7,7 & 11,2 & 13,2 & 15 & 8,0 \\
\hline
\end{tabular}

* Médias seguidas de letras distintas na coluna diferem entre si pelo teste de Tukey a 5\% de probabilidade

O tratamento fungicida das sementes possibilitou a utilização de períodos de condicionamento mais prolongados para a classificação dos lotes sem levá-los à ausência da germinação, quando comparado com o procedimento tradicional sem tratamento fungicida. O tratamento fungicida das sementes não promoveu modificações acentuadas nas informações sobre o potencial fisiológico dos lotes avaliados, assim como, verificado por Marcos Filho \& Shioga (1981) em estudos realizados com sementes de soja. Em relação ao grau de umidade nas sementes após o envelhecimento acelerado tradicional (com água) com tratamento fungicida (Tabela 7), constatou-se que, para o condicionamento das sementes na temperatura de $40^{\circ} \mathrm{C}$, não houve diferenças na umidade das sementes entre os lotes nos períodos de $24 \mathrm{e}$ 120 horas de condicionamento. Nos demais períodos, os lotes 3 e 4 foram os de maior e o menor teor de água nas sementes, respectivamente. Para a temperatura de $43^{\circ} \mathrm{C}$, verificou-se que houve diferenças entre os lotes nos períodos de 48,72 e 120 horas de condicionamento e para a temperatura de $45^{\circ} \mathrm{C}$ apenas no período de 120 horas. Os teores de água após o envelhecimento acelerado foram de 27,5 a $33,8 \%$ para a temperatura de $40^{\circ} \mathrm{C}$, de 26,5 a $34,8 \%$ para a temperatura de $43^{\circ} \mathrm{C}$ e de 26,5 a $34,8 \%$ para a temperatura de $45^{\circ} \mathrm{C}$, porém dentro de cada período de envelhecimento a variação entre os teores dos lotes não deve ter afetado os resultados do teste, considerando os limites alertados por Marcos Filho (1999). 
TABELA 7. Teor de água de sementes de cinco lotes de aveia preta, tratadas com fungicida, após cinco períodos de condicionamento $\left(24,48,72,96,120\right.$ horas) à temperatura de 40,43 e $45^{\circ} \mathrm{C}$ para o teste de envelhecimento acelerado tradicional.

\begin{tabular}{|c|c|c|c|c|c|c|c|c|c|c|c|c|c|c|c|}
\hline \multicolumn{16}{|c|}{ Teor de água (\%) } \\
\hline \multirow{2}{*}{ Lotes } & \multicolumn{5}{|c|}{$40^{\circ} \mathrm{C}$} & \multicolumn{5}{|c|}{$43^{\circ} \mathrm{C}$} & \multicolumn{5}{|c|}{$45^{\circ} \mathrm{C}$} \\
\hline & $24 \mathrm{~h}$ & $48 \mathrm{~h}$ & $72 \mathrm{~h}$ & $96 \mathrm{~h}$ & $120 \mathrm{~h}$ & $24 \mathrm{~h}$ & $48 \mathrm{~h}$ & $72 \mathrm{~h}$ & $96 \mathrm{~h}$ & $120 \mathrm{~h}$ & $24 \mathrm{~h}$ & $48 \mathrm{~h}$ & $72 \mathrm{~h}$ & $96 \mathrm{~h}$ & $120 \mathrm{~h}$ \\
\hline 1 & 28,5 & 32,5 & 31,8 & 33,3 & 33,8 & 27,3 & 30,0 & 31,3 & 30,8 & 32,5 & 27,5 & 29,8 & 31,3 & 32,5 & 32,0 \\
\hline 2 & 27,5 & 31,5 & 32,5 & 32,3 & 32,3 & 26,8 & 28,0 & 29,8 & 31,8 & 31,0 & 27,5 & 31,0 & 30,5 & 31,8 & 32,8 \\
\hline 3 & 29,8 & 33,3 & 33,5 & 34,3 & 33,0 & 28,0 & 30,0 & 33,0 & 33,3 & 34,8 & 28,5 & 30,3 & 31,8 & 33,8 & 34,5 \\
\hline 4 & 29,5 & 29,8 & 31,5 & 31,5 & 31,5 & 26,5 & 27,8 & 29,8 & 30,5 & 30,8 & 26,5 & 29,5 & 33,0 & 31,3 & 30,8 \\
\hline 5 & 28,8 & 32,8 & 33,3 & 33,5 & 33,3 & 28,8 & 30,5 & 32,5 & 32,3 & 33,8 & 29,3 & 31,5 & 33,8 & 33,0 & 34,0 \\
\hline
\end{tabular}

Pelos resultados obtidos pode-se observar que o teste de envelhecimento acelerado tradicional pode ser conduzido à temperatura de $40^{\circ} \mathrm{C}$ por 24 ou 48 horas e a 43 ou $45^{\circ} \mathrm{C}$ por 48 horas; o envelhecimento acelerado com solução saturada de sal a 40,43 ou $45^{\circ} \mathrm{C}$ por 24 horas e o envelhecimento acelerado tradicional com sementes tratadas a $40^{\circ} \mathrm{C}$ por 24 ou 48 horas, a $43^{\circ} \mathrm{C}$ por 48 horas ou a $45^{\circ} \mathrm{C}$ por 24 horas de condicionamento.

\section{CONCLUSÕES}

O teste de envelhecimento acelerado é adequado para estimar o vigor de sementes de aveia preta pelo procedimento tradicional (com e sem tratamento fungicida) ou com solução saturada de sal, ambos à temperatura de $40^{\circ} \mathrm{C}$ por 24 horas.

\section{REFERÊNCIAS}

BORSATO, A.V.; BARROS, A.S.R.; AHRENS, D.C.; DIAS, M.C.L.L. Avaliação de testes de vigor para sementes de aveia-branca (Avena sativa L.). Revista Brasileira de Sementes, v.22, n.1, p.163-168, 2000.

BRASIL, Ministério da Agricultura e Reforma Agrária. Regras para análises de sementes. Brasília, DF: SNAD/ CLAV, 1992. 365p.

CARVALHO, N.M.; NAKAGAWA, J. Sementes: ciência, tecnologia e produção. 4. ed. Jaboticabal: FUNEP, 2000. 588 p.

COMISSÃO ESTADUAL DE SEMENTES E MUDAS. Padrão de sementes de gramíneas forrageiras. [S.l.], 2001.

DERPSCH, R.; CALEGARI, A. Plantas para adubação verde de inverno. Londrina: IAPAR, 1992. 80p. (Circular, 73)

DIAS, D.C.F.S.; BHERING, M.C.; TOKUHISA, D. Teste de envelhecimento acelerado para avaliação do vigor de sementes de pimenta. In: CONGRESSO BRASILEIRO DE SEMENTES, 13., 2003, Curitiba. Resumos... Londrina: ABRATES, 2003. p.272.

GARCIA, D.C.; MENEZES, N.L. Teste de envelhecimento precoce para sementes de azevém, aveia preta e milheto. Ciência Rural, Santa Maria, v.29, n.2, p. 233-237, 1999.

HAMPTON, J.G.; TEKRONY, D.M. Handbook of vigour test methods. Zurich: ISTA, 1995.117p.

JIANHUA, Z.; McDONALD, M.B. The saturated salt accelerated aging test for small-seeded crops. Seed Science and Technology, v.25, n.1, p.123-131, 1996.

MARCOS FILHO, J. Teste de envelhecimento acelerado. In: VIEIRA, R.D.; CARVALHO, N.M. Testes de vigor em sementes. Jaboticabal: FUNEP, 1994. p.133-149.

MARCOS FILHO, J. Teste de envelhecimento acelerado. In: KRZYZANOWSKI, F.C.; VIEIRA, R.D.; FRANÇA NETO, J.B. (Ed.) Vigor de sementes: conceitos e testes. Londrina: ABRATES, 1999. p.3.1-3.24.

MARCOS FILHO, J.; SHIOGA, P.S. Tratamento fungicida de sementes de soja no teste de envelhecimento rápido. Revista de Agricultura, v.56, n.3, p.163-172, 1981.

MARCOS FILHO, J.; CÍCERO, S.M.; SILVA, W.R. Avaliação da qualidade das sementes. Piracicaba: FEALQ, 1987. 230p.

McDONALD MB. Standardization of seed vigour tests. In: CONGRESS OF THE INTERNATIONAL SEED TESTING ASSOCIATION, 24. Proceedings... Copenhagen: ISTA, 
1995. p.88-97.

McDONALD, M.B. ; PHANEENDRANATH, B.R. A modified accelerated aging seed vigor test for soybeans. Journal of Seed Technology, v.3, n.1, p. 27-37, 1978.

McDONALD, M.B.; GUPTA, I.J.; SCHMITTHENNER, A.F. Effect of storage fungi on seed vigour of soybean. Seed Science and Technology, v.21, n.3, p.581-591, 1993.

NAKAGAWA, J. Testes de vigor baseados na avaliação de plântulas. In: VIEIRA, R. D.; CARVALHO, N. M. (Ed.) Testes de vigor em sementes. FUNEP: Jaboticabal, 1994. $164 p$.

NAKAGAWA, J.; CAVARIANI, C. ; MACHADO, J.R. Maturação de sementes de aveia-preta (Avena strigosa Schreb.) I. Maturidade do campo. Pesquisa Agropecuária Brasileira, v.29, n.2, p.315-326, 1994.

NAKAGAWA, J.; CAVARIANI, C. ; MACHADO, J.R. Efeitos da dose e da época de aplicação de $\mathrm{N}$ na produção e qualidade de sementes de aveia-preta. Científica, v.23, n.1, p.31-43, 1995.

PANOBIANCO, M.; MARCOS FILHO, J. Envelhecimento acelerado e deterioração controlada em sementes de tomate. Scientia Agricola, v.58, n.3, p.525-531, 2001.
PATERNIANI, R.S.; REIS, R.A.; VIEIRA, R.D.; RODRIGUES, L.R.A.; COAN, O. Avaliação de genótipos de aveia quanto a produção e qualidade fisiológica de sementes. Revista Brasileira de Sementes, v.17, n.1, p.36-41, 1995.

RODO, A.B.; PANOBIANCO, M.; MARCOS FILHO, J. Metodologia alternativa do teste de envelhecimento acelerado para sementes de cenoura. Scientia Agricola, v.57, p.289-292, 2000.

TORRES, S.B. Métodos para avaliação do potencial fisiológico de sementes de melão. 2002. 103f. Tese (Doutorado em Agronomia) - ESALQ/USP, Piracicaba.

VIEIRA, R.D.; KRZYZANOWSKI, F.C. Teste de condutividade elétrica. In: KRZYZANOWSKI, F.C.; VIEIRA, R.D.; FRANÇA NETO, J.B. (Ed.) Vigor de sementes: conceitos e testes. Londrina: ABRATES, 1999. p.4.1-4.26.

WETZEL, C.T. Contribuição ao estudo da aplicação do teste de envelhecimento visando a avaliação do vigor em sementes de arroz (Oryza sativa L.) trigo (Triticum aestivum L.) e de soja [Glycine $\max$ (L.) Merril]. 1972. 116f. Dissertação (Mestrado em Agronomia) - ESALQ/USP, Piracicaba. 